\title{
Model Arsitektur Smart Library di Perguruan Tinggi Se-Kota Batam
}

\author{
Holong Marisi Simalango ${ }^{1 *}$, Muhammad Khaerul Naim Mursalim²** \\ * Teknik Perangkat Lunak, Universitas Universal \\ ** Teknik Telekomunikasi, Universitas Universal \\ simalangoholong@gmail.com¹,muh.khaerul.naim@gmail.com²
}

\begin{tabular}{l}
\hline Article Info \\
\hline Article history: \\
Received ... \\
Revised ... \\
Accepted ... \\
\hline
\end{tabular}

\section{Keyword:}

Smart library,

Web services,

Open Access,

Internet of Things (IoT),

Object Oriented Analysis

(OOA).

\begin{abstract}
Design of smart library architecture model is a new architectural model of integrating library information systems in several universities that still use WebApp but are local, so that it is expected to be connected to the new architectural design. The design of this model focuses on the use of web services, the application of the concept of Open access by utilizing QR Code as an Internet of Things (IoT). This design focuses on the technology that will be used to integrate library information systems in all universities, especially in the city of Batam. Object Oriented Analysis (OOA) is a methodology used in designing smart library architecture models and using Unified Modeling Language (UML). Architectural design consists of business architecture, information architecture, and technology architecture. Business architecture design modeling is described in the business use case explaining the actors namely students and library staff as well. The results of the design of the smart library architecture model are in the form of design recommendations for the construction of smart libraries at universities in the city of Batam. The design of this smart library architecture model with the application of technological trends will provide convenience and support to the academic community in the use of library systems.
\end{abstract}

Copyright (C) 2019 Journal of Applied Informatics and Computing. All rights reserved.

\section{Pendahuluan}

Perguruan Tinggi yang berada di Kota Batam terdapat swasta dan negeri, dimana Perguruan Tinggi pertama kali didirikan pada tahun 1993, kemudian diikuti pendirian Perguruan Tinggi baru hingga tahun ini. Perguruan Tinggi yang berdiri lama telah banyak menghasilkan alumnus dan mengumpulkan buku karya ilmiah di perpustakaan masingmasing perguruan tinggi. Setiap Perguruan Tinggi memiliki sistem informasi perpustakaan yang berbentuk WebApp yang bersifat local ataupun online, namun tidak menampilkan semua informasi baik itu artikel tugas akhir, skripsi, dan penelitian ataupun buku yang disediakan secara terbuka.

Pada masa ini kata "plagiat" adalah hal yang sangat dihindari di dunia pendidikan. Para mahasiswa tingkat akhir biasanya kebingungan dan terlalu memikirkan kewaspadaan terhadap plagiat. Beberapa mahasiswa mencari referensi sebagai tugas akhir, skripsi, dan penelitian dengan menelusuri menggunakan penelurusan secara online yaitu Google ataupun mendatangi perpustakaan Perguruan Tinggi terdekat. Mahasiswa kelas karyawan sangat kebingungan untuk mencari referensi, dikarenakan terbatasnya waktu untuk bekerja di hari biasa, dan beberapa Perguruan Tinggi terdapat jadwal kuliah di hari sabtu juga. Mahasiswa jaman sekarang lebih sering menggunakan smartphone untuk melakukan pencarian data atau informasi dengan cepat, baik itu dalam bentuk artikel atau e-Book [1] sebagai referensi.

Penerapan sistem terintegrasi sedang tren di sebuah organisasi atau perusahaan. Penerapan sistem terintegrasi juga bisa digunakan sebagai jembatan penghubung sistem instansi tertentu yang berbeda framework yang dimana tujuan yang sama. Pengintegrasian sistem dapat diterapkan pada sistem informasi perpustakaan pada beberapa perguruan tinggi, karena memiliki fungsi dan tujuan utama yang sama dari sebuah sistem informasi perpustakaan. Pengintegrasian sistem ini juga memanfaatkan web services dan sekalian menerapkan konsep Open access yang dapat memicu setiap Perguruan Tinggi semakin memperhatikan untuk keterbukaan data-data artikel karya ilmiah. Beberapa penelitian untuk mengintegrasikan sistem informasi sudah pernah dilakukan, salah satunya menggunakan teknologi berbasis web service [2] [3]. 
Penelitian ini didasarkan dari penelitian sebelumnya bahwa pemanfaatan smartphone untuk layanan digital library serta membahas bagaimana mengatasi kecepatan respon dan tekanan dari server ketika menggunakan sistem ini. Pada sistem ini memiliki fitur untuk memberikan layanan rekomendasi buku yang disesuaikan dengan informasi dari pengguna [4]. Penelitian lainnya yang mendasari pengembangan sistem informasi perpustakaan dengan pemanfaatan teknologi hijau yang akan mengurangi konsumsi energi dan revolusi teknologi cerdas [5]. Selain itu juga penelitian yang memaparkan konsep RFID untuk otomasi data KTP [6] dan smart library untuk satu perpustakaan yang menggunakan teknologi Radio Frequency Identification (RFID) dan Mobile (IoT) untuk melacak rincian transaksi perpustakaan dan informasi tentang buku di perpustakaan [7].

\section{Metodologi}

Strategi untuk mengadopsi konsep teknologi yang akan dikembangkan dengan perencanaan. Dalam perencanaan model arsitektur smart library yang harus ditentukan yaitu; siapa aja aktor yang berinteraksi dengan sistem perpustakaan dan apa saja sumber daya yang akan dipergunakan untuk mendukung perencanaan model arsitektur smart library. Lalu bagaimana prosedur pergantian sistem yang baru akan terapkan dengan sistem perpustakaan yang sedang berjalan. Untuk mencapai tujuan utama dari penelitian ini, perlu menggunakan metodologi penelitian pada gambar 1 sebagai berikut.

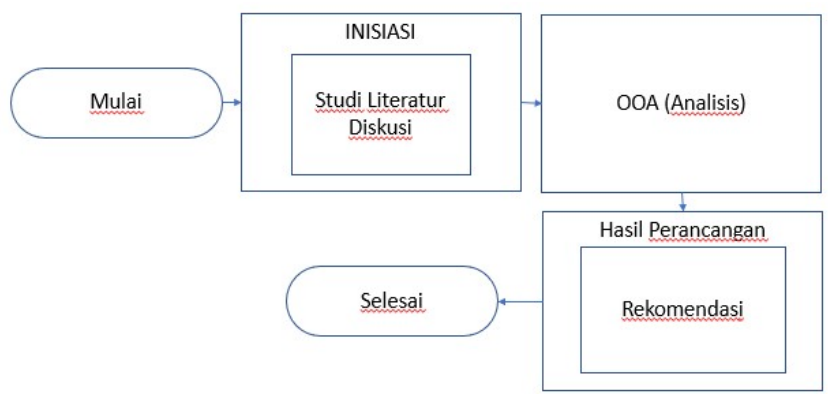

Gambar 1. Metodologi

Tahap awal inisiasi. Pada tahap inisiasi terdiri dari studi literatur dan diskusi. Studi literatur, proses yang dikerjakan pada tahap ini memahami konsep dasar dan teori untuk pondasi dalam perencanaan perancanagan sistem serta metode apa saja yang bisa digunakan untuk mengembangan sistem tersebut dilihat dari berbagai aspek seperti sisi bisnis serta dari sisi pengembangan aplikasi. Diskusi, mengumpulkan informasi ataupun rekomendasi dan saran dalan topik penelitian ini dari informan baik itu staf perpustakaan dan pakar di bidang teknologi informasi seperti dosen di bidang komputer. Hasil diskusi ini dirampungkan dan disusun ke bentuk pembahasan untuk perancangan konsep smart library.
Tahap selanjutnya Object Oriented Analysis (OOA). Pada metode analisis berorientasi objek mencakup representasi kelas dan hirarki kelas, model hubungan perilaku objek.

Tahap terakhir adalah rekomendasi. Pada tahap ini perancangan yang telah dilakukan dilakukan harus disusun secara akurat sesuai dengan proses dan aktifitas yang direnkomendasikan dalam model arsitektur smart library di Perguruan Tinggi se Kota Batam yang berisi rincian informasi, desain antar muka aplikasi, dan teknologi yang diperlukan instansi pada saat ini dan masa depan.

\section{Pembahasan}

\section{A. Rancangan Arsitektur Smart library}

IoT telah dipandang sebagai teknologi yang sangat menjajikan dengan potensi besar untuk dapat mengatasi berbagai masalah sosial [8]. Perancangan konsep smart library ini juga meruapakan gabungan dari konsep IoT, konsep Open Access (OA), dan konsep web service. Konsep IoT yang digunakan dengan pemanfaatan quick respond (QR) code. Penerapan konsep Open access (OA) pada perpustakaan untuk mempermudah dan membuka akses karya ilmiah dari beberapa perpustakaan, bahkan OA ini juga telah diterapkan oleh beberapa penerbit jurnal [9][10]. Saat ini web service adalah solusi dalam integrasi sistem karena tanpa melihat platform, arsitektur maupun bahasa pemrograman yang digunakan oleh sumber berbeda [2].

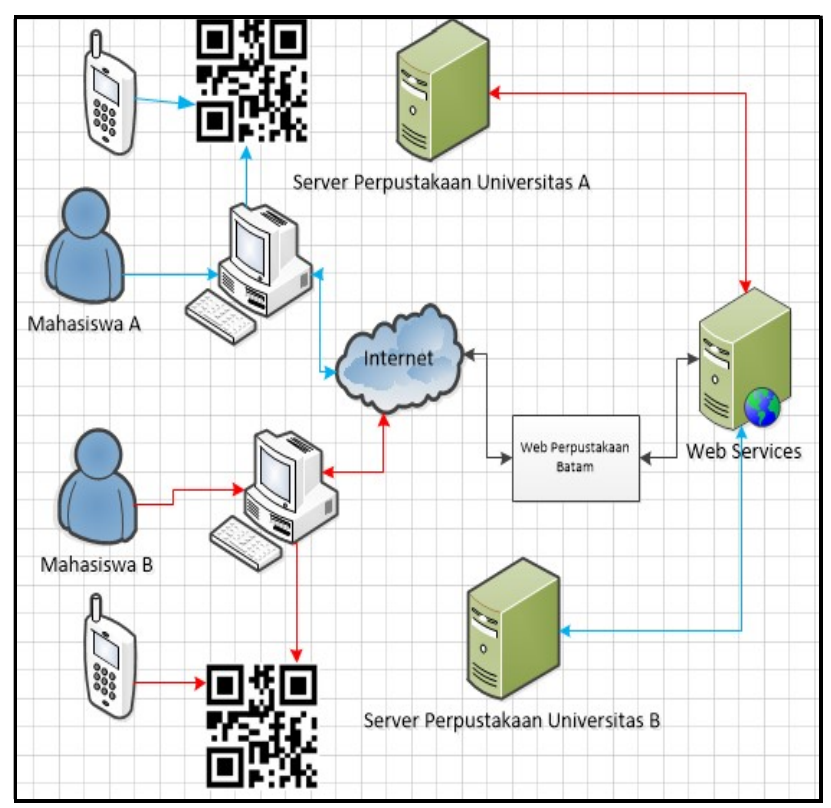

Gambar 2. Rancangan Arsitektur Smart library

Mahasiswa dari Universitas A mengakses digital library menggunakan komputer perpustakaan universitas A, pada digital library tersebut akan ditambahkan menu untuk akses Web Perpustakaan Batam. Web Perpustakaan Batam bisa diakses hanya melalui dengan komputer di perpustakaan yang sudah direkam Mac Address dari setiap komputer perpustakaan, sehingga jika ingin menggunakan piranti 
lainnya, Web Perpustakaan Batam tidak dapat diakses. Web Perpustakaan Batam bisa terkoneksi dengan Server Perpustakaan Universitas B yang dihubungkan dengan Web services. Mahasiswa A dapat membaca langsung dari web dan memarkah artikel yang akan dibaca melalui smartphone. Pada Situs Perpustakaan Batam menampilkan QR Code untuk pengaksesan artikel yang dimarkah melalui smartphone. Mahasiswa hanya dengan memakai perangkat lunak untuk scan QR Code yang ditampilkan, secara otomatis akan diarahkan ke Web Perpustakaan Batam, namun hanya bisa melihat artikel yang sudah dimarkah dan memiliki session. Fungsi session yaitu untuk pembatasan mahasiswa akses kembali ke web tersebut. Jika sudah terjadi pemutusan session, maka QR Code sebelumnya tidak bisa dipergunakan lagi dan harus mengakses kembali Web Perpustakaan dari komputer perpustakaan. Web Perpustakaan Batam secara otomatis menghasilkan QR Code yang unik ketika diakses oleh setiap mahasiswa. Proses yang terjadi untuk Mahasiswa A juga sama halnya dengan Mahasiswa B.

\section{B. Use case yang Diusulkan}

Use case adalah sesuatu atau proses yang merepresentasikan hal-hal yang dapat dilakukan oleh aktor dalam menyelesaikan sebuah pekerjaan. Sebuah use case dapat include fungsionalitas use case lain sebagai bagian dari proses dalam dirinya [11]. Use case diagram digunakan untuk menggambarkan interaksi antara satu aktor dengan aktor lainnya dan fungsi apa yang ada di dalam sistem.

Klasifikasi aktor terdiri dari dua jenis, yakni actor sebagai manusia dan actor sebagai piranti. Aktor sebagai manusia. Aktor yang berinteraksi dengan sistem, yaitu mahasiswa, staf perpustakaan, dan administrator. Aktor sebagai piranti. Aktor yang bukan manusia, akan tetapi memiliki peran dalam interaksi dengan sistem yaitu smartphone.

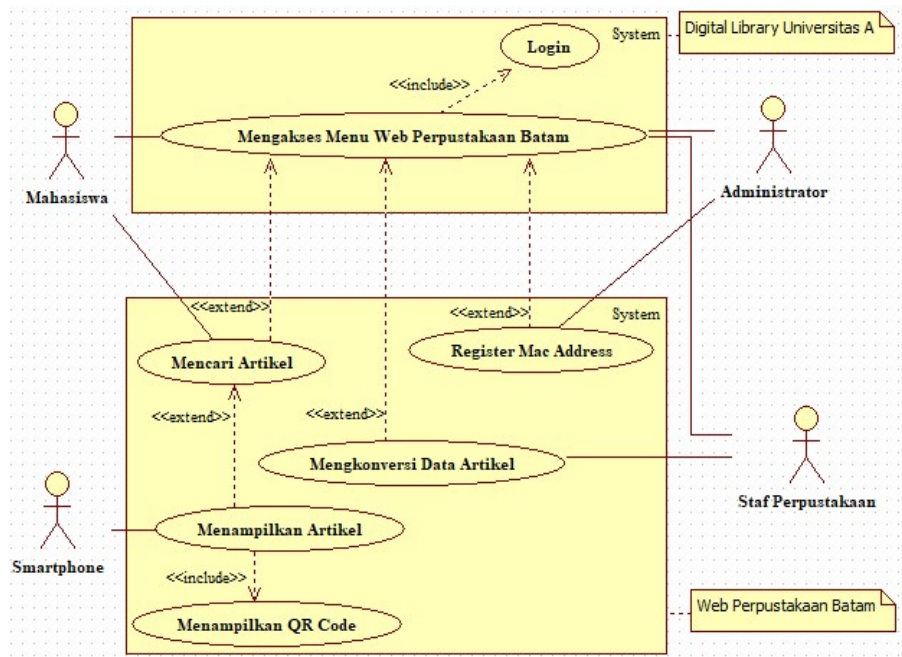

Gambar 3. Use case diagram yang diusulkan

Pada usecase diagram di gambar 3 terdiri dari sistem yaitu digital library tiap perguruan tinggi dan sistem lainnya Web untuk menjembatani digital library dengan server perpustakaan perguruan tinggi lainnya. Pada use case diagram ini melibatkan empat aktor, diantaranya mahasiswa, administrator, staf perpustakaan, dan smartphone.

Aktor mahasiswa sebagai aktor yang berinteraksi dengan digital library perguruan tingginya yaitu melakukan login, kemudian akan melakukan akses ke menu Web perpustakaan batam. Ketika telah dapat akses web perpustakaan batam juga dapat mencari artikel karya ilmiah, memarkah artikel agar dapat dibaca di smartphone mahasiswa dengan scan QR code yang otomatis generate oleh web perpustakaan batam.

Aktor staf perpustakaan sebagai aktor yang berinteraksi dengan sistem untuk registrasi mac address komputer dan mengkonversikan data artikel karya ilmiah. Sedangkan aktor administrator sebagai aktor yang berinteraksi dengan sistem untuk register mac address komputer perpustakaan di perguruan tinggi di Kota Batam.

Use case Login, merupakan proses yang harus dilakukan sebelum menggunakan akses digital library dan Web Perpustakaan Batam. Use case mengakses Menu Web Perpustakaan Batam, merupakan proses untuk terhubung ke web Perpustakaan Batam. Use case Mencari artikel, merupakan proses yang dilakukan mahasiswa untuk pencarian data-data artikel dan memiliki fungsi lain untuk memarkah artikel yang akan dibaca. Use case Menampilkan QR code, merupakan proses yang lebih dulu terjadi sebelum menampilkan artikel. Pada proses ini sistem akan menampilkan QR code yang unik. Use case Menampilkan Artikel, merupakan proses untuk menampilkan data-data artikel yang telah dimarkah, namun pada proses ini terdapat variabel session. Use case Register MacAddress, proses untuk mendaftarkan mac address dari komputer tertentu di perpustakaan yang akan dipakai pada proses akses Web Perpustakaan. Use case Mengkonversi data artikel merupakan proses yang terjadi dari staf perpustakaan mengkonversi data-data apa saja yang dibutuhkan dalam konversi data dengan penggunaan alias nama field.

\section{KESIMPULAN}

Perancangan model Smart library dapat dijadikan rekomendasi dalam penerapan smart library untuk mengintegrasikan beberapa digital library perguruan tinggi di Kota Batam. Pihak perguruan tinggi bekerja sama dalam membuka database untuk mengintegrasikan data khususnya data karya ilmiah mahasiswa untuk dapat diakses oleh mahasiswa dari perguruan tinggi lainnya secara digital. Konsep smart library ini merupakan gabungan dari konsep IoT dan konsep Open Access (OA) yang sangat besar manfaat dalam penunjang kebutuhan di kebutuhan sivitas akademik. Konsep teknologi dan pemahaman IoT sangat besar manfaatnya di berbagai bidang agar tercapainya penerapan Revolusi Teknologi 4.0 di bidang pendidikan. Hasil rekomendasi dapat diperluas untuk konversi data menjadi alias field dari penyimpanan data artikel di Perguruan Tinggi dengan kata kunci yang diperlukan di Web Perpustakaan Batam. Sebagai saran, ketepatan hasil 
rekomendasi tergantung dari pemahaman untuk menerapkan konsep web services dan open access dalam mengintegrasi beberapa sistem tanpa mempersoalkan framework.

\section{UCAPAN TERIMA KASIH}

Terimakasih kepada Kemenristekdikti yang mendanai luaran untuk penelitian dosen pemula, dan Universitas Universal yang segenap memberikan dukungan kepada penulis.

\section{DAFTAR PUSTAKA}

[1] N. Z. Janah, Y. Rokhayati, D. E. Kurniawan, and M. F. Muvariz, 'Electronic School Books Dissemination Application for Batam Hinterland Schools', Adv. Sci. Lett., vol. 24, no. 12, pp. 9739-9744, 2018

[2] A. Ramatulloh, dkk.," Keamanan RESTful Web service Menggunakan JSON Web Token (JWT) HMAC SHA-512", JNTETI, Vol. 7, No 2, hal 131-137, Mei 2018.

[3] R. Parahita, dkk., "Sistem Informasi Perhotelan Berbasis Web Service: Studi Kasus Di Pulau Lombok", J-COSINE, Vol. 1, No. 1, hal 46-52, Des. 2017.

[4] H. Li, Z. Cai," Design and Implementation of The Mobile Library App Based on Smart Phone". Proceeding of the 2016 International
Conference on Machine Learning and Cybernetics South Korea. hal 318-322, 2016.

[5] C. Jayalakshmi, R. Sarangapani, "Green Libraries by Using Smart Technology", 2017 International Conference on Smart Technology for Smart Nation, hal 1496-1499, 2017.

[6] D. Ely Kurniawan, A. Fatulloh, and N. Cahyono Kushardianto, 'Ship Ticketing System Using Near Field Communication (NFC) and SMS Gateway for Batam Island Transportation', in Proceedings of the Joint Workshop KO2PI and the 1st International Conference on Advance \& Scientific Innovation, 2018, pp. 32-38

[7] J. Pandey, dkk., "A Study on Implementation of Smart Library using IoT", 2017 International Conference on Infocon Technologies and Unmanned Systems (ICTUS), hal 193-197, 2017.

[8] B. Ahlgren, dkk., "Internet of Things for smart cities: Interoperability and Open Data", IEEE INTERNET COMPUTING, hal 56-62, 2016.

[9] D. E. Irawan, dkk., "Era baru publikasi di Indonesia: status jurnal open access di Directory of Open Access Jurnal (DOAJ)", BIP, Vol. 14, No. 2, hal 133-147, Des. 2018.

[10] K. Kiramang, "Perkembangan Penerbitan Jurnal Open Access dalam mendukung komunikasi ilmiah dan peranan perpustakaan perguruan tinggi", PUSTALOKA, Vol. 9, No. 2, hal. 185-202, Nov. 2017.

[11] M. R. Manalu, "Implementasi Sistem Informasi Penyewaan Mobil Pada CV. BTN Padang Bulan Dengan Metode Waterfall", Junral Mantik Penusa, Vol. 18, No. 2, hal. 34-43, Des. 2015. 